\title{
Specificity of respiratory pathways involved in the reduction of sulfur compounds by Salmonella enterica
}

\author{
Andrew P. Hinsley ${ }^{1}$ and Ben C. Berks ${ }^{1,2}$
}

1 Centre for Metalloprotein Spectroscopy and Biology, School of Biological Sciences, University of East Anglia, Norwich NR4 7TJ, UK

\section{Department of} Biochemistry, University of Oxford, South Parks Road, Oxford OX1 3QU, UK

\begin{abstract}
Author for correspondence: Ben C. Berks (at Oxford address). Tel: +44 1865 275250. Fax: +44 1865275259. e-mail: ben.berks@bioch.ox.ac.uk

The tetrathionate (Ttr) and thiosulfate (Phs) reductases of Salmonella enterica LT2, together with the polysulfide reductase (Psr) of Wolinella succinogenes, are unusual examples of enzymes containing a molybdopterin active-site cofactor since all formally catalyse sulfur-sulfur bond cleavage. This is in contrast to the oxygen or hydrogen transfer reactions exhibited by other molybdopterin enzymes. Here the catalytic specificity of Ttr and Phs has been compared using both physiological and synthetic electron-donor systems. Ttr is shown to catalyse reduction of trithionate but not sulfur or thiosulfate. In contrast, Phs cannot reduce tetrathionate or trithionate but allows whole cells to utilize elemental sulfur as an electron acceptor. Mechanisms are proposed by which the bacterium is able to utilize an insoluble sulfur substrate by means of reactions at the cytoplasmic rather than the outer membrane.
\end{abstract}

Keywords: tetrathionate reductase, thiosulfate reductase, polysulfide reductase, molybdopterin, electron transport

\section{INTRODUCTION}

Sulfur in the zero-valent oxidation state is able to form a variety of compounds containing chains of sulfur atoms linked by sulfur-sulfur bonds. These include elemental sulfur $\left(\mathrm{S}_{8}\right)$, polysulfides $\left({ }^{-} \mathrm{S}-(\mathrm{S})_{n}-\mathrm{S}^{-}\right)$, sulfane monosulfonates $\left({ }^{-} \mathrm{S}-\left(\mathrm{S}_{n}\right)-\mathrm{SO}_{3}^{-}\right)$and polythionates $\left({ }^{-} \mathrm{O}_{3} \mathrm{~S}-(\mathrm{S})_{n}-\mathrm{SO}_{3}^{-}\right)$, where in each case $n \geqslant 0$. A range of bacteria are able to use these inorganic sulfur species as respiratory electron acceptors by reductively cleaving the sulfur-sulfur bonds (Barrett \& Clark, 1987; Hedderich et al., 1998). Recent studies have revealed that in many cases the enzymes catalysing these reductive cleavage reactions contain a bis (molybdopterin guanine dinucleotide)molybdenum (MGD) cofactor at the catalytic site. The most prominent examples of such enzymes are the tetrathionate ( $\mathrm{Ttr}$ ) and thiosulfate (Phs) reductases of the enteric bacterium Salmonella enterica LT2 and the polysulfide reductase (Psr) of the rumen bacterium Wolinella succinogenes, which catalyse reactions (1)-(3) respectively (Pollock \& Knox, 1943; Hensel et al., 1999; Klimmek et al., 1991; Clark \& Barrett, 1987).

$$
{ }^{-} \mathrm{O}_{3} \mathrm{~S}-\mathrm{S}-\mathrm{S}-\mathrm{SO}_{3}^{-}+2 \mathrm{e}^{-} \rightarrow 2{ }^{-} \mathrm{S}-\mathrm{SO}_{3}^{-}
$$

Abbreviation: MGD, bis(molybdopterin guanine dinucleotide)molybdenum.

$$
\begin{aligned}
& { }^{-} \mathrm{S}_{-} \mathrm{SO}_{3}^{-}+2 \mathrm{e}^{-}+2 \mathrm{H}^{+} \rightarrow \mathrm{HS}^{-}+\mathrm{HSO}_{3}^{-} \\
& { }^{-} \mathrm{S}-(\mathrm{S})_{n}-\mathrm{S}^{-}+2 \mathrm{e}^{-}+\mathrm{H}^{+} \rightarrow^{-} \mathrm{S}-(\mathrm{S})_{n-1}-\mathrm{S}^{-}+\mathrm{HS}^{-}
\end{aligned}
$$

The use of a molybdopterin cofactor to catalyse these reactions is intriguing since this cofactor normally catalyses oxygen atom transfer, hydrogen atom transfer or a combination of the two (Hille, 1996; Khangulov et al., 1998). The enzymes carrying out sulfur bond cleavage (which might alternatively be styled sulfur atom transfer) therefore operate a previously undescribed biological reaction of the molybdopterin cofactor. Sequence similarities between the MGD-binding subunits of Ttr, Phs and Psr in the polypeptide region that contributes to the enzyme active-site pocket and substrate-access channel support the idea that these proteins form a specificity grouping distinct from other MGD-dependent enzymes (Hensel et al., 1999; Fig. 1).

In this study we have compared the catalytic specificities of the S. enterica Ttr and Phs enzymes in the light of the proposal that these enzymes, together with Psr, have similar catalytic mechanisms. Mutant strains lacking either Ttr or Phs, or lacking both these enzymes, were used to allow discrimination between the activity of the two enzymes in whole cells. Some experiments also employed strains lacking the enzyme dissimilatory sulfite reductase (Asr), which reduces sulfite to sulfide (Huang \& Barrett, 1990). We have investigated whether 
TtrA-like proteins

$\begin{array}{lll}\text { Salmonella enterica } & \text { TtrA } & \text { DEGRDAFLRRFALNSFGSKNFGAHGAYCGLAYRAGSGALMG } \\ \text { Yersinia enterocolitica } & \text { TtrA } & \text { DDGRDAFIQREANQAFGTKNLGSHGAYCGLAYRAGSGALMG } \\ \text { Pasteurella multocida } & \text { TtrA } & \text { PEGRQPLLKRFANNSFGTINFASHGSF CGLSYRAGSGAFMN } \\ \text { Bordetella parapertussis } & \text { NEGRTPLIQRFAAQSFGTVNVSNHGSYCGQSFRVGTGAAFG } \\ \text { Desulfitobacterium hafniense } & \text { DDGRTPFAKREVNNAYGSPNHFGHGGICGISRRVAYLAFLD } \\ \text { Carboxydothermus hydrogenoformans } & \text { GDRRDFEKERFWSQTLGSINSLDHGGICGVNGVIGNVQSFN } \\ \text { Dehalococcoides ethenogenes } & \text { QGGRVDFIKRFTHDAMGSINAHGHTTVGGSLFOSAKALSA }\end{array}$

PhsA/PsrA-like proteins

$\begin{array}{lrl}\text { Salmonella enterica } & \text { PhsA } & \text { KSGSLSSHLFHLATAFGSPNTFTHASTCPAGKAIAAKVMMG } \\ \text { Shewanella putrefasciens } & \text { KSGSQEKHLFHLATAFGSPNTFTHASTCEGGYEIAAKAMFG } \\ \text { Wolinella succinogenes } & \text { PsrA } & \text { RSGWNKTWFHHLAQAYGSPNIFGHESTCPLAYNMAGRDVFG } \\ \text { Carboxydothermus hydrogenoformans } & \text { HPELAYDYEVIFNQAFGSPNLSAHAPTC } \\ \text { Desulfovibrio vulgaris } & \text { RGGPFMDLHQAFVRGLGSPNYCNHDASCARNVQHACRSVTG } \\ \text { Porphyromonas gingivalis } & \text { RGGPFMDLHQAFVRGLGSPNYCNHDACCARNVQHACRSVTG }\end{array}$

Fig. 1. Multiple sequence comparison of the polypeptide region that provides an amino acid ligand to the molybdenum atom of MGD-dependent sulfur-sulfur bond reductases. The cysteine residue that is proposed (Hensel et al., 1999) to co-ordinate the molybdenum atom in the sulfur-sulfur bond reductases is boxed.

the catalytic abilities of the active-site cofactors of $\mathrm{Ttr}$ and $\mathrm{Phs}$ are restricted to their physiological reactions. We have also explored whether these enzymes are able to reduce other inorganic sulfur compounds containing sulfur-sulfur bonds.

\section{METHODS}

Bacterial culture conditions. Bacterial strains and plasmids used in this study are described in Table 1. Unless otherwise stated bacteria were cultured on Luria broth (LB) or LB agar at $37^{\circ} \mathrm{C}$ (Sambrook et al., 1989). Antibiotics were used at the following concentrations : tetracycline, $10 \mu \mathrm{g} \mathrm{ml}^{-1}$; ampicillin, $50 \mu \mathrm{g} \mathrm{ml}^{-1}$; kanamycin $50 \mu \mathrm{g} \mathrm{ml}^{-1}$.

For experiments in which tetrathionate induction of the tr $B C A$ operon was desired, S. enterica was grown in anoxic liquid culture using the standardized protocol described by Hensel et al. (1999). For experiments in which induction of the phs $A B C$ operon was desired, S. enterica was grown to an $\mathrm{OD}_{600}$ of 0.4 in anoxic liquid culture supplemented with $50 \mathrm{mM} \mathrm{Na} \mathrm{S}_{2} \mathrm{O}_{3}$. In both case the cells were harvested by centrifugation, washed three times in ice-cold $10 \mathrm{mM}$ sodium phosphate buffer $(\mathrm{pH} \mathrm{7.4)}$ and then used immediately for the assay of interest.

Table 1. Strains and plasmids used in this study

\begin{tabular}{|c|c|c|}
\hline $\begin{array}{l}\text { Strain or } \\
\text { plasmid }\end{array}$ & Relevant genotype/characteristics & Source or reference \\
\hline \multicolumn{3}{|l|}{ S. enterica } \\
\hline $\mathrm{LT} 2 \mathrm{a}$ & Parental & B. N. Ames \\
\hline EB222 & phs-101::Mu d1 (Ap ${ }^{\mathrm{r}}$ lac) & Clark \& Barrett (1987) \\
\hline EB231 & phs-109::Tn10 $\left(\right.$ Tet $\left.^{\mathrm{r}}\right)$ & Clark \& Barrett (1987) \\
\hline EB303 & cysI68 asr $-1:: \operatorname{Tn} 5\left(\operatorname{Kan}^{\mathrm{r}}\right)$ & Huang \& Barrett (1990) \\
\hline BCB6 & $\operatorname{tr} A:: \operatorname{Tn} 10\left(\operatorname{Tet}^{\mathrm{r}}\right)$ & Hensel et al. (1999) \\
\hline APH8 & phs-101::Mu d1 asr-1::Tn5 & $\begin{array}{l}\text { P22 transduction } \\
(\mathrm{EB} 222 \times \mathrm{EB} 303)\end{array}$ \\
\hline APH12 & $\operatorname{ttr} A:: \operatorname{Tn} 10$ phs-101::Mu d1 asr-1::Tn5 & $\begin{array}{l}\mathrm{P} 22 \text { transduction } \\
(\mathrm{APH} 8 \times \mathrm{BCB} 6)\end{array}$ \\
\hline APH14 & $\operatorname{ttr} A:: \operatorname{Tn} 10$ asr $-1:: \operatorname{Tn} 5$ & $\begin{array}{l}\text { P22 transduction } \\
(\text { EB222 } \times \text { APH8) }\end{array}$ \\
\hline \multicolumn{3}{|l|}{ E. coli } \\
\hline MC4100 & $\mathrm{F}^{-}$AlacU169 ara139 rpsL150 relA1 ptsF rbs flbB5301 & $\begin{array}{l}\text { Casadaban \& Cohen } \\
\text { (1979) }\end{array}$ \\
\hline \multicolumn{3}{|l|}{ Plasmids } \\
\hline pAH26 & $\operatorname{ttrRSBCA}$ in $\mathrm{pSU} 41$ & Hensel et al. (1999) \\
\hline pAH65 & pAH26 bearing an Ala for Cys change at $t$ trA codon 256 & This work \\
\hline pAH66 & pAH26 bearing a Ser for Cys change at $t$ trA codon 256 & This work \\
\hline pNH650 & phs $A B C$ & E. L. Barrett \\
\hline
\end{tabular}


For anaerobic growth on solid media, plates were incubated in gas jars under a nitrogen $/ \mathrm{CO}_{2}$ atmosphere generated using the Anaerogen system (Oxoid). Tests for growth on the nonfermentable carbon source glycerol utilized the minimal medium described by Pope \& Cole (1982) but lacking the nutrient broth component and supplemented with $30 \mathrm{mM}$ glycerol and the electron acceptor of interest. Dispersed elemental sulfur was introduced into solid media by air oxidation of plates prepared with a polysulfide solution as described by Moser \& Nealson (1996).

Genetic techniques. Standard molecular genetic techniques were carried out as described by Sambrook et al. (1989). P22mediated transductions were performed as detailed in Maloy et al. (1996) using P22 HT int. Point mutations at the Cys256 TGT codon in ttrA were constructed using the Quick Change System (Stratagene). The new codons, GCT for the Ala mutation and TCT for the Ser mutation, were first introduced into the $X b a \mathrm{I}$ fragment of $t \operatorname{tr} A$ that bears codon 256 and then used to replace the corresponding $\mathrm{XbaI}$ wild-type fragment in pAH26.

Analytical methods. Trithionate was synthesized as described by Kelly \& Wood (1994). Tetrathionate, trithionate and thiosulfate concentrations were determined by cyanolysis according to the protocols of Kelly \& Wood (1994). Assays for methyl-viologen-linked activities and for polysulfide reductase activity were carried out in glass cuvettes sealed with a butyl rubber stopper and rendered anoxic by bubbling with oxygenfree nitrogen. For the methyl-viologen-linked measurements the assay solution contained $10 \mathrm{mM}$ sodium phosphate buffer $\mathrm{pH} 7 \cdot 4,2 \mathrm{mM} \mathrm{Na}{ }_{2}$ EDTA and $1 \mathrm{mM}$ methyl viologen. The methyl viologen was reduced by titration with a $\mathrm{Ti}$ (III) citrate solution until the $A_{600}$ reached $1 \cdot 5$. The reaction was started by the addition of electron acceptor, and oxidation of methyl viologen radical was monitored at $600 \mathrm{~nm}\left[\Delta \varepsilon_{600}\left(\mathrm{MV}^{\bullet+}-\right.\right.$ $\left.\left.\mathrm{MV}^{2+}\right)=13 \mathrm{mM}^{-1} \mathrm{~cm}^{-1}\right]$. Electron acceptors were used at the following concentrations: $500 \mu \mathrm{M}$ potassium tetrathionate; $500 \mu \mathrm{M}$ potassium trithionate; $1 \mathrm{mM}$ sodium thiosulfate. Tetrathionate and trithionate reductase assays had to be corrected for the rate of chemical reduction of the substrate by the methyl viologen radical. For measurement of polysulfide reductase activity the assay buffer was $50 \mathrm{mM}$ Tris $/ \mathrm{HCl}$, $\mathrm{pH} 8 \cdot 3$. Polysulfide was added to a concentration of $1 \mathrm{mM}$ from a stock solution prepared from sodium sulfide and sulfur flowers as described by Moser \& Nealson (1996). Bacteria were introduced into the cuvette, following which the assay was initiated by addition of $10 \mathrm{mM}$ sodium formate to act as electron donor to the bacterial electron-transfer chain. Reduction of polysulfide was monitored via the decrease in $A_{360}$ using $\Delta \varepsilon=0.38 \mathrm{mM}^{-1} \mathrm{~cm}^{-1}$ (Klimmeck et al., 1998).

\section{RESULTS AND DISCUSSION}

\section{Similarity of active sites probed by mutagenesis of a conserved cysteine residue}

A consequence of the proposal that Ttr, Phs and Psr have related mechanisms is that conserved amino acids in the putative active-site regions of these proteins should be important for catalysis. Prominent amongst these residues is a cysteine which is invariant amongst the MGD enzymes involved in sulfur-sulfur bond cleavage (Fig. 1) and which has been suggested to be the amino acid ligand to the active-site molybdenum atom of the MGD cofactor (Hensel et al., 1999). To investigate the importance of this conserved cysteine this residue was substituted with, separately, serine and alanine in the $\operatorname{Ttr} A$ catalytic subunit of $S$. enterica tetrathionate reductase. The site-specific mutations were introduced into a plasmid-borne copy of the $t$ tr locus and expressed heterologously in Escherichia coli. As previously reported (Hensel et al., 1999) the wild-type ttr locus confers on E. coli the ability to assemble the Ttr complex and to respire tetrathionate. However, E. coli cells expressing either of the cysteine mutants were unable to reduce tetrathionate either with physiological electron donors or with the synthetic electron donor methyl viologen radical $\left(\mathrm{MV}^{\cdot+}\right)$ (Table 2). The conserved 'active site' cysteine is thus essential for the production of functional tetrathionate reductase. It was not possible to determine if the variant catalytic subunits had been successfully targeted to the membrane since immunoblotting showed that even the wild-type plasmidexpressed TtrA polypeptide localizes predominantly to the cytoplasmic compartment. Attempts to circumvent this problem by transferring the mutations to the $S$. enterica chromosome were unsuccessful. Nevertheless the effects of the substitution mutations are consistent with the view that the invariant cysteine residue is critically important for the operation of the Ttr catalytic site.

\section{The active sites of $S$. enterica tetrathionate and thiosulfate reductases catalyse distinct reactions}

Under normal physiological conditions tetrathionate reductase plays no part in the reduction of thiosulfate (Clark \& Barrett, 1987). However, since Ttr and Phs have been inferred to catalyse the same classes of reactions it is possible that the inability of Ttr to mediate physiological thiosulfate reduction is not due to mechanistic reasons but rather to the low potential of the electron acceptor couple $\left[E^{0 \prime}\left(\mathrm{S}_{2} \mathrm{O}_{3}^{2-} / \mathrm{HS}^{-}+\mathrm{HSO}_{3}^{-}\right)=\right.$ $-400 \mathrm{mV}$ ] relative to those of the physiological electron donors to $\operatorname{Ttr}$ (ubiquinol $\left[E^{0 \prime}\left(\mathrm{UQ} / \mathrm{UQH}_{2}\right)=\right.$ $+113 \mathrm{mV}]$ and menaquinol $\left[E^{0 \prime}\left(\mathrm{MQ} / \mathrm{MQH}_{2}\right)=\right.$ $-75 \mathrm{mV}])$. To test this idea we grew a $p h s$ strain on tetrathionate-containing medium to induce Ttr expression and then measured thiosulfate reductase activity with the low-potential reductant methyl viologen radical $\left[E^{0 \prime}\left(\mathrm{MV}^{2+} / \mathrm{MV}^{\cdot+}\right)=-450 \mathrm{mV}\right]$ as electron donor. It is generally considered that viologen radicals are capable of donating electrons directly to the active-site molybdenum cofactor of MGD-containing enzymes. The $p h s$ mutant exhibited no detectable $\mathrm{MV}^{\cdot+}$-linked thiosulfate reductase activity while an activity of $160 \mathrm{nmol} \mathrm{MV}^{\cdot+}$ oxidized $\min ^{-1}$ (mg protein $)^{-1}$ was measured for an isogenic $p h s^{+}$strain induced for Phs expression. Thus, $\mathrm{Ttr}$ is unable to catalyse thiosulfate reduction even when provided with an electron donor of appropriate potential.

Phs does not contribute to physiological tetrathionate oxidation (Hensel et al., 1999). However, it is not clear that $\mathrm{Phs}$ is expressed while tetrathionate is present in the growth medium. It was therefore possible that Phs lacks physiological tetrathionate reductase activity not for 
Table 2. Testing the involvement of conserved Cys $256_{\mathrm{TtrA}}$ in the catalytic activity of $S$. enterica tetrathionate reductase

\begin{tabular}{|c|c|c|c|}
\hline \multirow[t]{2}{*}{ Strain } & \multicolumn{2}{|c|}{$\begin{array}{l}\text { Physiological tetrathionate reduction } \\
\text { (LB medium) }\end{array}$} & \multirow{2}{*}{$\begin{array}{l}\text { Tetrathionate reductase } \\
\text { activity }\left[\mathrm{nmol} \mathrm{MV}^{\cdot+}\right. \\
\text { oxidized } \mathrm{min}^{-1} \\
\left.(\mathrm{mg} \text { protein })^{-1}\right]\end{array}$} \\
\hline & $\begin{array}{l}\text { Tetrathionate } \\
\text { consumed }(\mathrm{mM})\end{array}$ & $\begin{array}{c}\text { Thiosulfate } \\
\text { produced }(\mathrm{mM})\end{array}$ & \\
\hline MC4100 & 0 & 0 & 16 \\
\hline MC4100/pAH26 (ttrRSBCA) & 8 & 16 & 110 \\
\hline $\begin{array}{l}\text { MC4100/pAH65 }(t t r R S B C A \\
\text { Cys256 } \\
\text { Ttra } \rightarrow \text { Ala })\end{array}$ & 0 & 0 & 7 \\
\hline $\begin{array}{l}\text { MC4100/pAH66 (ttrRSBCA } \\
\text { Cys256 } 6_{\operatorname{Ttr} A} \rightarrow \text { Ser) }\end{array}$ & 0 & 0 & 12 \\
\hline
\end{tabular}

mechanistic reasons but because it is not expressed under the appropriate growth conditions. This idea was tested by measuring tetrathionate reductase activity in a ttr mutant that had been grown under conditions suitable for the induction of Phs synthesis. No significant tetrathionate reductase activity could be measured in these cells with either $\mathrm{MV}^{\cdot+}$ or physiological electron donors even though thiosulfate reductase activity was easily detected. This experiment suggests that Phs is not mechanistically capable of reducing tetrathionate.

\section{Ttr and Phs are capable of oxygen atom transfer}

It has previously been reported that Phs is capable of reducing chlorate to chlorite (Riggs et al., 1987). This is a significant observation because the reduction of chlorate involves an oxygen atom transfer rather than the sulfur-sulfur bond cleavage of the physiological thiosulfate reduction reaction. To test whether Ttr is also capable of oxygen atom transfer we cultured $p h s$ and phs ttr mutants in the presence of tetrathionate to induce Ttr expression, and then measured $\mathrm{MV}^{\cdot+}$-linked chlorate reductase activity in whole cells. A specific chlorate reductase activity of $190 \mathrm{nmol} \mathrm{MV}{ }^{\cdot+}$ oxidized $\min ^{-1}$ (mg protein $)^{-1}$ was measured for the strain APH8 (ttr ${ }^{+}$phs asr) compared to $70 \mathrm{nmol} \mathrm{MV}{ }^{\cdot+}$ oxidized $\mathrm{min}^{-1}$ (mg protein) ${ }^{-1}$ for strain APH12 (ttr phs asr). Thus the $\mathrm{Ttr}^{+}$strain had a chlorate reductase activity almost three times higher than that of the $\mathrm{Ttr}^{-}$strain. The S. enterica membrane-bound nitrate reductase is also known to have chlorate reductase activity (Barrett \& Riggs, 1982). Control measurements showed that both the $\mathrm{Ttr}^{+}$and $\mathrm{Ttr}^{-}$strains had low, but identical, nitrate reductase activities [ $29 \mathrm{nmol} \mathrm{MV}^{\cdot+}$ oxidized $\mathrm{min}^{-1}(\mathrm{mg} \text { protein })^{-1}$ ], indicating that the difference in chlorate reductase activity between the strains cannot be ascribed to nitrate reductase. This experiment suggests that Ttr has chlorate reductase activity and that the Ttr molybdopterin cofactor is capable of oxygen atom transfer.

Azide is a specific inhibitor of some molybdopterindependent enzymes (e.g. membrane-bound nitrate reductases: Craske \& Ferguson, 1986; E. coli formate
dehydrogenase-H: Axley et al., 1990). However, azide at a concentration of $100 \mu \mathrm{mol} \mathrm{^{-1 }}$ did not inhibit the tetrathionate reductase activity of $\mathrm{Ttr}$ or the thiosulfate reductase activity of Phs.

\section{Reduction of trithionate by S. enterica}

It was of interest to determine whether the Ttr enzyme specifically reduces tetrathionate or whether it is also able to cleave polythionate compounds with other chain lengths. Trithionate $\left({ }^{-} \mathrm{O}_{3} \mathrm{~S}-\mathrm{S}-\mathrm{SO}_{3}^{-}\right)$can be formed by the facile chemical reaction of tetrathionate and sulfite (reaction 4) and is therefore likely to be present in many tetrathionate-containing environments.

$$
{ }^{-} \mathrm{O}_{3} \mathrm{~S}-\mathrm{S}-\mathrm{S}-\mathrm{SO}_{3}^{-}+\mathrm{SO}_{3}^{2-} \rightarrow{ }^{-} \mathrm{O}_{3} \mathrm{~S}-\mathrm{S}-\mathrm{SO}_{3}^{-}+\mathrm{S}_{2} \mathrm{O}_{3}^{2-}
$$

We found that $S$. enterica is capable of anaerobic growth on the non-fermentable carbon source glycerol with trithionate as sole respiratory electron acceptor. This growth was dependent on the Ttr enzyme since $t t r$ mutants failed to grow under these culture conditions. In contrast, trithionate-linked growth was unaffected in a phs mutant. E. coli strain MC4100 was found to be unable to utilize trithionate as terminal electron acceptor. However, introduction of plasmid pAH26 carrying the ttrRSBCA cluster allowed growth of this strain on trithionate, confirming that $\mathrm{Ttr}$ is responsible for trithionate-dependent growth.

The products of the trithionate reduction reaction were examined in wild-type $S$. enterica LT2a during growth on minimal glycerol medium. For each mole of trithionate consumed approximately one mole of thiosulfate and one mole of sulfite were produced. This suggests that trithionate is reduced by $\mathrm{Ttr}$ in a reaction (equation $5)$ analogous to that of tetrathionate reduction.

$$
{ }^{-} \mathrm{O}_{3} \mathrm{~S}-\mathrm{S}-\mathrm{SO}_{3}^{-}+2 \mathrm{e}^{-} \rightarrow \mathrm{S}_{2} \mathrm{O}_{3}^{2-}+\mathrm{SO}_{3}^{2-}
$$

The ability of $\mathrm{Ttr}$ and of Phs to reduce trithionate was also tested using the non-physiological electron donor $\mathrm{MV}^{\cdot+}$. Cells cultured in the presence of trithionate exhibited similar rates of $\mathrm{MV}^{\cdot+}$-linked trithionate and tetrathionate reduction. This trithionate reductase ac- 


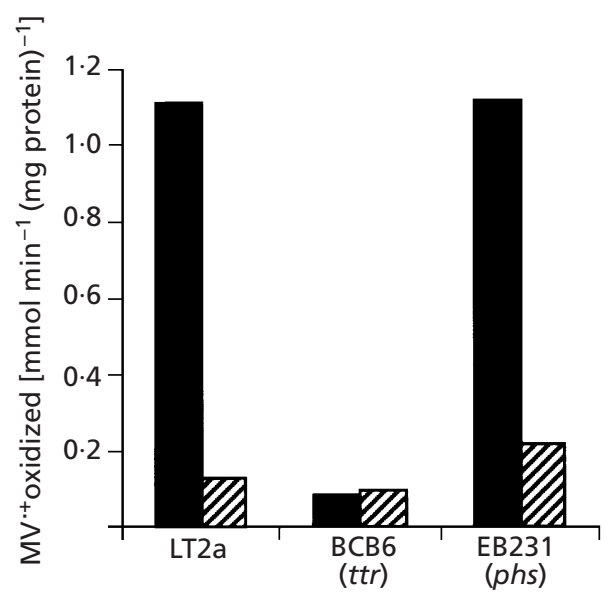

Fig. 2. S. enterica tetrathionate reductase catalyses trithionate reduction. The figure shows the methyl viologen radicaldependent rate of trithionate reduction by washed whole cells. Strains were precultured anoxically on LB medium either in the presence (filled bars) or absence (striped bars) of tetrathionate.

tivity was absent from a $t$ tr but not a $p h s$ strain, demonstrating that trithionate reduction requires $\mathrm{Ttr}$ (Fig. 2). To be sure that Phs does not have trithionate reductase activity the $t t r$ mutant was cultured in the presence of thiosulfate rather than trithionate to ensure high Phs expression. Even under these conditions of Phs induction no significant methyl-viologen-dependent trithionate reduction could be measured.

Taken together these data suggest that trithionate is a substrate for Ttr but not Phs. It is not possible to determine by competition experiments whether tetrathionate or trithionate is the preferred substrate of $\mathrm{Ttr}$ since if trithionate is metabolized (reaction 5) the product sulfite will react with tetrathionate according to reaction 4 to give a net reaction identical to that of tetrathionate reduction (reaction 1).

Expression of the ttrBCA operon requires the TtrSR two-component regulator and is induced by tetrathionate (Hensel et al., 1999; Price-Carter et al., 2001). It is probable that tetrathionate is sensed directly by $\mathrm{TtrS}$ since thiosulfate, the product of tetrathionate metabolism, does not induce Ttr expression. In this study we found that Ttr was induced in medium lacking tetrathionate but containing trithionate. This suggests that trithionate is capable of inducing $\mathrm{Ttr}$ synthesis and therefore that TtrS may be capable of sensing both trithionate and tetrathionate.

\section{Reduction of elemental sulfur by S. enterica}

We investigated whether the sulfur-sulfur bonds of elemental sulfur were also amenable to cleavage by $S$. enterica. Solid medium containing dispersed solid sulfur was prepared by air oxidation of agar plates to which an alkaline polysulfide solution had been added at the time of pouring.
S. enterica LT2a was capable of anaerobic growth on LB agar plates containing $50 \mathrm{mM}$ formate and $10 \mathrm{mM}$ elemental sulfur. The opaque elemental sulfur precipitate within the plates cleared around the colonies, indicating that the insoluble sulfur had been converted to another species by bacterial metabolism (Fig. 3a). In the absence of formate, which acts as a direct electron donor to the respiratory electron transfer chain, sulfur clearing still occurred but was not as extensive. Sulfur clearing was also observed on solid minimal medium containing $50 \mathrm{mM}$ formate with $0 \cdot 4 \%$ lactate as carbon source. E. coli, which does not utilize inorganic sulfur compounds as respiratory electron acceptors, did not exhibit the sulfur-clearing phenotype (Fig. 3a). Sulfide (up to $5 \mathrm{mM}$ ) could be detected in cultures of $S$. enterica growing anaerobically in liquid LB medium in the presence of sulfur powder, suggesting that sulfide is the product of the sulfur dissolution reaction. Significant quantities of tetrathionate or thiosulfate were not detected in these liquid cultures.

To ascertain whether any of the enzymes tetrathionate reductase, thiosulfate reductase or anaerobic sulfite reductase were involved in the sulfur-clearing phenotype, strains with $t t r$, phs and asr null mutations were cultured on LB-sulfur-formate plates. The sulfur-clearing phenotype was absent in the phs mutant (Fig. 3a). In contrast, sulfur clearing was unaffected in $t t r$ and $a s r$ mutants (Fig. 3a). Plasmid pNH650 carrying the $S$. enterica phs $A B C$ operon directs functional expression of thiosulfate reductase in E. coli (Fong et al., 1993). We found that pNH650 also confers the sulfur-clearing phenotype on E. coli (Fig. 3a). This observation confirms the link between sulfur-clearing and Salmonella thiosulfate reductase.

Elemental sulfur did not support growth of S. enterica in the presence of a non-fermentable carbon source. This observation is congruent with the involvement of Psr in sulfur reduction since $S$. enterica cannot grow by thiosulfate respiration alone. Instead thiosulfate reduction functions to augment growth on fermentable carbon sources (Heinzinger et al., 1995; A. P. Hinsley \& B. C. Berks unpublished).

Sulfur clearing by S. enterica was prevented by addition of $30 \mathrm{mM}$ tetrathionate to the plates. This tetrathionate inhibition was relieved in a $t$ tr mutant, indicating that tetrathionate must be metabolized to suppress sulfur clearing. Addition of $20 \mathrm{mM}$ thiosulfate to the sulfur plates did not inhibit sulfur clearing. This shows that it is not the product of the Ttr reaction that is responsible for suppression of sulfur clearing. Instead the effect of tetrathionate is most likely due to the preferential routeing of reducing equivalents to $\mathrm{Ttr}$ rather than $\mathrm{Phs}$, a hierarchy previously observed in the differential utilization of tetrathionate and thiosulfate (e.g. Hensel et al., 1999).

Mechanisms for the sulfur-clearing phenotype in which the cells directly reduce elemental sulfur can be ruled out since (i) the sulfur clearing extends far beyond direct contact with the cells (Fig. 3a), (ii) sulfide production 
(a)

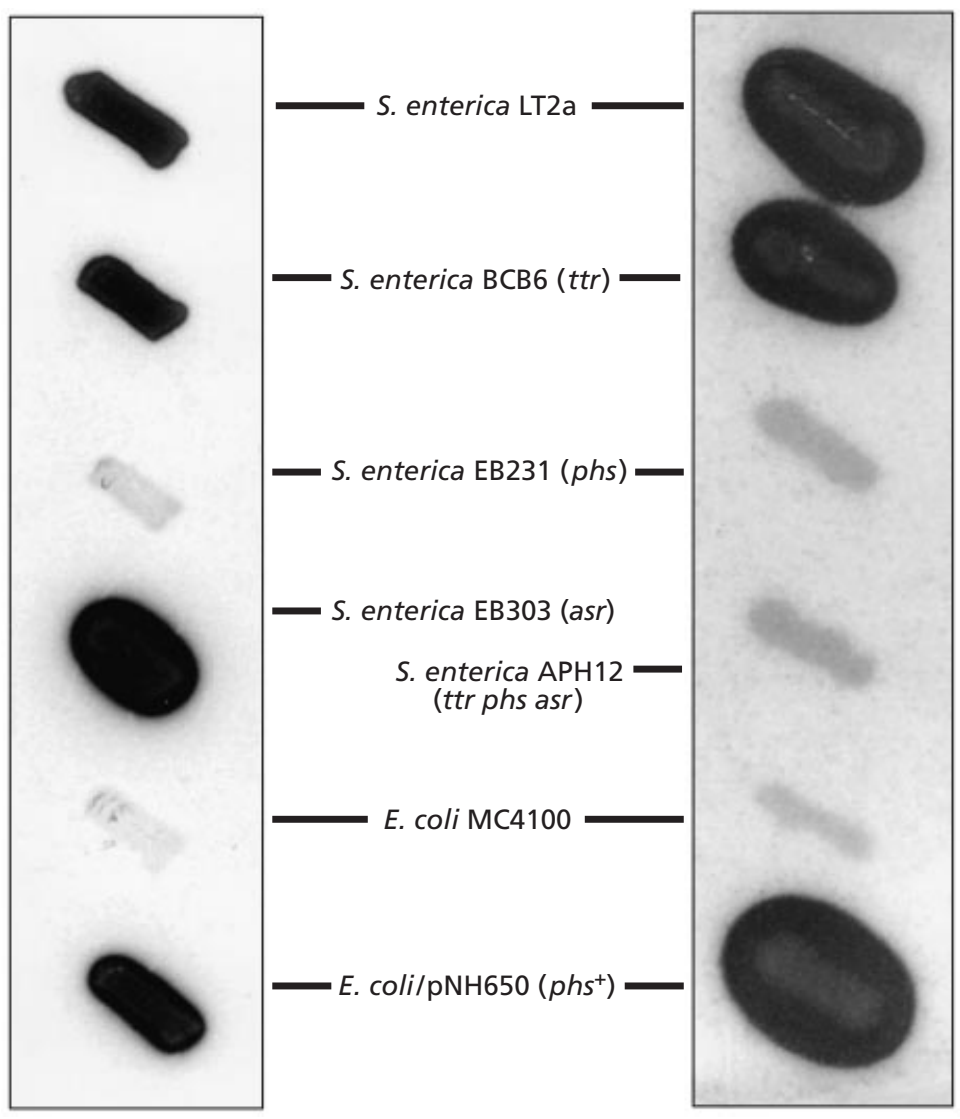

Fig. 3. Metabolism of elemental sulfur in $S$. enterica is associated with thiosulfate reductase activity. (a) Strains were streaked on an LB agar plate containing $50 \mathrm{mM}$ sodium formate and $10 \mathrm{mM}$ sulfur. The plate was then incubated anoxically under a nitrogen $/ \mathrm{CO}_{2}$ atmosphere at $37^{\circ} \mathrm{C}$ for $72 \mathrm{~h}$. (b) As (a) except that the agar was supplemented with $50 \mathrm{mM}$ NaMES $\mathrm{pH} 6.0$ and the plate was incubated for $120 \mathrm{~h}$. Utilization of sulfur is manifest as clearing of the opaque sulfur substrate. In this figure the plates have been placed on a black background to allow clearing to be visualized as a dark region around the bacterial streak. from sulfur can still be measured in liquid culture when either the cells or the sulfur powder are placed inside a sealed dialysis sac and (iii) the thiosulfate reductase active site is in the periplasmic compartment, which the insoluble sulfur substrate cannot access. Two possible models are suggested for the metabolism of sulfur by $S$. enterica using water-soluble species: thiosulphate cycling and polysulfide reduction.

The thiosulfate cycling model (Fig. 4a) assumes that trace quantities of thiosulfate are present in the sulfur plates. This is not unreasonable since the stock polysulfide solution has been oxidized by molecular oxygen. The thiosulfate is metabolized by the normal Phs reaction (overall equation 6). The product sulfite molecule, produced at the periplasmic face of the inner membrane, diffuses away from the cell and reacts by well-established and facile chemistry with elemental sulfur producing thiosulfate (equation 7). Since reaction (7) produces one mole of thiosulfate for each mole of thiosulfate reduced in equation (6) the combination of the two reactions results in the reduction of elemental sulfur to sulfide, with thiosulfate having a catalytic role in the process (equation 8). Possible support for the thiosulfate cycling mechanism comes from the observation that strains that are capable of thiosulfate reduction but are unable to reduce the sulfite product (the $S$. enterica asr mutant and E. coli expressing $p h s)$ reproducibly show larger zones of sulfur clearing than strains that can reduce both thiosulfate and sulfite (Fig. 3a).

$$
\begin{aligned}
& \mathrm{S}_{2} \mathrm{O}_{3}^{2-}+\mathrm{H}^{+}+2 \mathrm{e}^{-} \rightarrow \mathrm{HS}^{-}+\mathrm{SO}_{3}^{2-} \\
& n / 8 \mathrm{~S}_{8}+\mathrm{SO}_{3}^{2-} \rightarrow \mathrm{S}_{2} \mathrm{O}_{3}^{2-} \\
& n / 8 \mathrm{~S}_{8}+\mathrm{H}^{+}+2 \mathrm{e}^{-} \rightarrow \mathrm{HS}^{-}
\end{aligned}
$$

In the polysulfide reduction model (Fig. $4 \mathrm{~b}$ ), which is analogous to the mechanism of sulfur reduction found in W. succinogenes (Klimmek et al., 1991; Hedderich et al., 1998), elemental sulfur is converted to water-soluble polysulfides by reaction with sulfide (formal equation 9). The polysulfide is then reduced by $\mathrm{Phs}$ using overall equation (10). This mechanism requires either that trace quantities of polysulfide remain in the plates following oxidation or that bacterial metabolism provides small amounts of sulfide to initiate the reaction. Once reaction (10) is operative the sulfide produced will mobilize additional elemental sulfur.

$(n-1) / 8 \mathrm{~S}_{8}+\mathrm{HS}^{-} \leftrightarrow \mathrm{S}_{n}^{2-}+\mathrm{H}^{+}$

$S_{n}^{2-}+n \mathrm{H}^{+}+2 n \mathrm{e}^{-} \rightarrow n \mathrm{HS}^{-}$

The polysulfide reduction mechanism requires that $\mathrm{Phs}$ can operate as a polysulfide reductase. However, we found that washed cells of S. enterica that had been induced for Phs expression did not reduce polysulfide with formate as electron donor. Similarly no polysulfide reductase activity could be detected with cells induced for Ttr expression. A caveat with these measurements is 
(a)

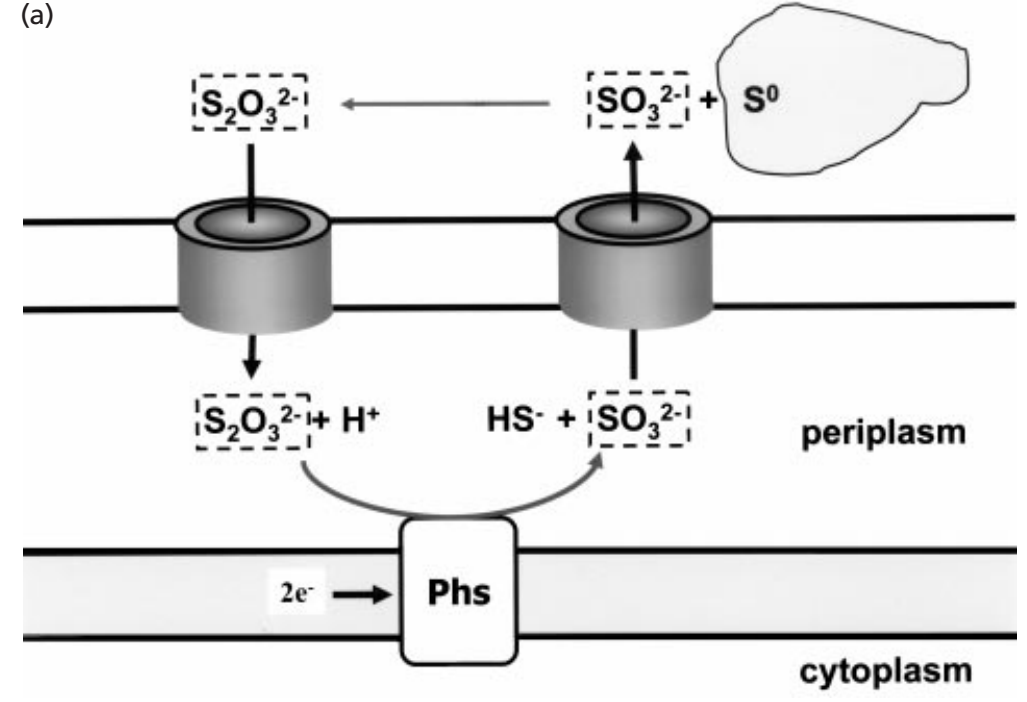

(b)

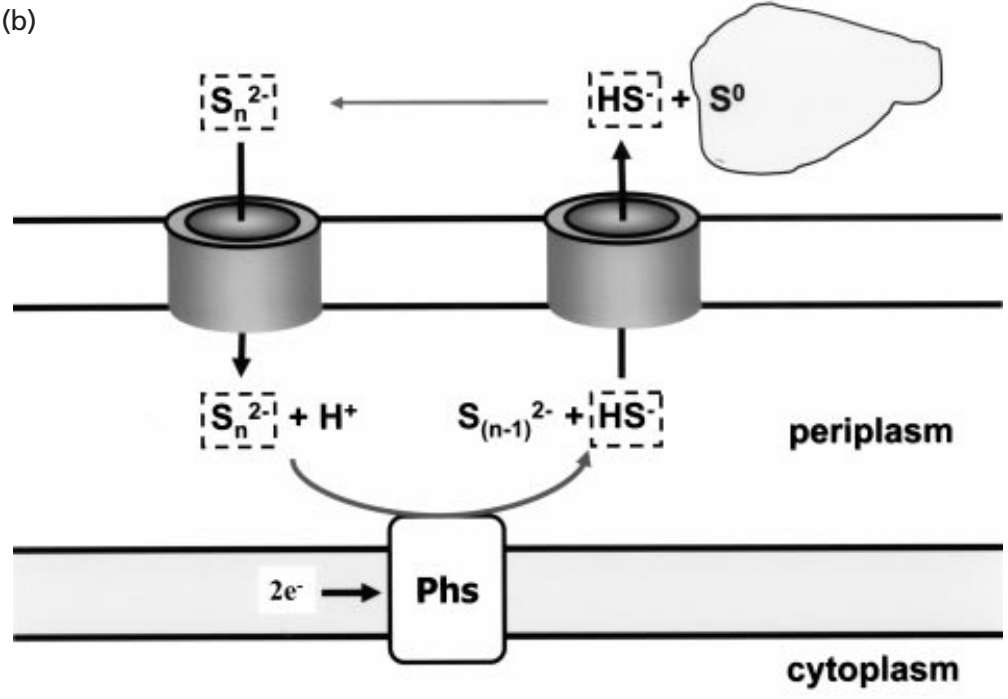

Fig. 4. Two biochemical models for the sulfur-clearing phenotype of S. enterica. (a) Thiosulfate cycling model, in which sulfur solid is mobilized by reaction with sulfite. (b) Polysulfide reduction model, in which sulfur solid is mobilized by reaction with sulfide. In both schemes the water-soluble species are depicted as traversing the outer membrane through porins. that the polysulfide assay is relatively insensitive and might not pick up low-level polysulfide reductase activity [of the order of $10 \mathrm{nmol}$ polysulfide sulfur reduced $\min ^{-1}$ (mg protein $)^{-1}$ or less] associated with Phs. Nevertheless, our polysulfide reductase activity measurements provide no positive support for the idea that a polysulfide reduction mechanism is operating during sulfur clearing by $S$. enterica. It is also worth noting that addition of $20 \mathrm{mM}$ thiosulfate to the plates did not inhibit the sulfur-clearing reaction (above). Since thiosulfate is a known substrate of Phs, such a high concentration of thiosulfate would be expected to competitively inhibit any polysulfide reductase activity of the enzyme if it existed.

Polysulfides are unstable at low $\mathrm{pH}$, disproportionating to elemental sulfur and sulfide according to equation (9). We considered that an analysis of the $\mathrm{pH}$ dependence of the sulfur-clearing phenotype catalysed by $S$. enterica might give insight into the possible involvement of polysulfides in the process. The ability of S. enterica to clear sulfur was tested on LB-formate-sulfur plates buffered by means of a $50 \mathrm{mM}$ concentration of an appropriate Good buffer. A range of $\mathrm{pH}$ values in the interval 6.0-9.0 was examined. While sulfur clearing was most efficient at high $\mathrm{pH}$ the phenotype was still detectable at $\mathrm{pH} 6.0$ (Fig. 3b). The solubility of polysulfide in a $10 \mathrm{mM}$ solution of sulfide at $\mathrm{pH} 6.0$ and $37^{\circ} \mathrm{C}$ is approximately $10 \mu \mathrm{M}$ (Schauder \& Kröger, 1993). Since it is highly unlikely that the concentration of sulfide available in the plates to initiate polysulfide formation is anywhere near $10 \mathrm{mM}$, the concentration of free polysulfide in the $\mathrm{pH} 6.0$ plates that could act as a potential Phs substrate will be a great deal less than $10 \mu \mathrm{M}$. We infer that a polysulfide reduction mechanism alone cannot account for the sulfur-clearing phenotype. Our observations suggest that Salmonella species are capable of utilizing elemental sulfur as an electron acceptor in natural environments. They also raise the 
possibility that a thiosulfate cycling system could mediate sulfur respiration in other organisms. It is notable that both the thiosulfate cycling system and the polysulfide-based reactions provide a mechanism by which a substrate that cannot cross the outer membrane can be metabolized by means of reactions taking place at the cytoplasmic membrane (Fig. 4).

\section{ACKNOWLEDGEMENTS}

We would like to thank Professor Erika Barrett for providing strains and plasmids used in this study and Jason Southgate for technical assistance. This work was supported by grant 83/P11074 from the Biotechnology and Biological Research Council of the United Kingdom. B.C.B. is RJP Williams Senior Research Fellow at Wadham College, Oxford.

\section{REFERENCES}

Axley, M. J., Grahame, D. A. \& Stadtman, T. C. (1990). Escherichia coli formate-hydrogen lyase. Purification and properties of the selenium-dependent formate dehydrogenase component. J Biol Chem 265, 18213-18218.

Barrett, E. L. \& Clark, M. A. (1987). Tetrathionate reduction and production of hydrogen sulfide from thiosulfate. Microbiol Rev 51, 192-205.

Barrett, E. L. \& Riggs, D. L. (1982). Evidence for a second nitrate reductase activity that is distinct from the respiratory enzyme in Salmonella typhimurium. J Bacteriol 150, 563-571.

Casadaban, M. J. \& Cohen, S. N. (1979). Lactose genes fused to exogenous promoters in one step using a $\mathrm{Mu}$-lac bacteriophage: in vivo probe for transcriptional control sequences. Proc Natl Acad Sci US A 76, 4530-4533.

Clark, M. A. \& Barrett, E. L. (1987). The phs gene and hydrogen sulfide production by Salmonella typhimurium. J Bacteriol 169, 2391-2397.

Craske, A. \& Ferguson, S. J. (1986). The respiratory nitrate reductase of Paracoccus denitrificans. Molecular characterization and kinetic properties. Eur J Biochem 158, 429-436.

Fong, C.-L. W., Heinzinger, N. K., Tongklan, S. \& Barrett, E. L. (1993). Cloning of the phs genetic locus from Salmonella typhimurium and a role for a phs product in its own induction. J Bacteriol 175, 6368-6371.

Hedderich, R., Klimmek, O., Kröger, A., Dirmeier, R., Keller, M. \& Stetter, K. O. (1998). Anaerobic respiration with sulfur, polysulfide and disulfide. FEMS Microbiol Rev 22, 353-381.

Heinzinger, N. K., Fujimoto, S. Y., Clark, M. A., Moreno, M. S. \& Barrett, E. L. (1995). Sequence analysis of the phs operon in
Salmonella typhimurium and the contribution of thiosulfate reduction to anaerobic energy metabolism. J Bacteriol 177, 2813-2820.

Hensel, M., Hinsley, A. P., Nikolaus, T., Sawers, G. \& Berks, B. C. (1999). The genetic basis of tetrathionate respiration in Salmonella typhimurium. Mol Microbiol 32, 275-288.

Hille, R. (1996). The mononuclear molybdenum enzymes. Chem Rev 96, 2757-2816.

Huang, C. J. \& Barrett, E. L. (1990). Identification and cloning of genes involved in anaerobic sulfite reduction by Salmonella typhimurium. J Bacteriol 172, 4100-4102.

Kelly, D. P. \& Wood, A. (1994). Synthesis and determination of thiosulphate and polythionates. Methods Enzymol 243, 475-501.

Khangulov, S. V., Gladyshev, V. N., Dismukes, G. C. \& Stadtman, T. C. (1998). Selenium-containing formate dehydrogenase $H$ from Escherichia coli: a molybdopterin enzyme that catalyzes formate oxidation without oxygen transfer. Biochemistry 37, 3518-3528.

Klimmek, O., Kröger, A., Steudel, R. \& Holdt, G. (1991). Growth of Wolinella succinogenes with polysulphide as terminal acceptor of phosphorylative electron transport. Arch Microbiol 155, 177-182.

Klimmek, O., Kreis, V., Klein, C., Simon, J., Wittershagen, A. and Kröger, A. (1998). The function of the periplasmic Sud protein in polysulfide respiration of Wolinella succinogenes. Eur J Biochem 253, 263-269.

Maloy, S. R., Stewart, V. J. \& Taylor, R. K. (1996). Genetic Analysis of Pathogenic Bacteria. Cold Spring Harbor, NY: Cold Spring Harbor Laboratory.

Moser, D. P. \& Nealson, K. H. (1996). Growth of the facultative anaerobe Shewanella putrefaciens by elemental sulfur reduction. Appl Environ Microbiol 62, 2100-2105.

Pollock, M. R. \& Knox, R. (1943). Bacterial reduction of tetrathionate. Biochem J 37, 476-481.

Pope, N. R. \& Cole, J. A. (1982). Generation of a membranepotential by one of two independent pathways for nitrite reduction by Escherichia coli. J Gen Microbiol 128, 219-222.

Price-Carter, M., Tingey, J., Bobik, T. A. \& Roth, J. R. (2001). The alternative electron acceptor tetrathionate supports $B_{12}$-dependent anaerobic growth of Salmonella enterica serovar Typhimurium on ethanolamine or 1,2-propanediol. J Bacteriol 183, 2463-2475.

Riggs, D. L., Tang, J. S. \& Barrett, E. L. (1987). Thiosulfate reductase as a chlorate reductase in Salmonella typhimurium. FEMS Microbiol Lett 44, 427-430.

Sambrook, J., Fritsch, E. F. \& Maniatis, T. (1989). Molecular Cloning: a Laboratory Manual, 2nd edn. Cold Spring Harbor, NY : Cold Spring Harbor Laboratory.

Schauder, R. \& Kröger, A. (1993). Bacterial sulfur respiration. Arch Microbiol 159, 491-497.

Received 27 May 2002; revised 15 August 2002; accepted 16 August 2002. 